\title{
Impact of land cover change on the climate of southwest Western Australia
}

\author{
A. J. Pitman and G. T. Narisma \\ Department of Physical Geography, Macquarie University, Sydney, Australia \\ R. A. Pielke Sr. \\ Department of Atmospheric Sciences, Colorado State University, Fort Collins, Colorado, USA \\ N. J. Holbrook \\ Department of Physical Geography, Macquarie University, Sydney, Australia
}

Received 12 November 2003; revised 24 June 2004; accepted 8 July 2004; published 23 September 2004.

[1] A sudden reduction in rainfall occurred in the southwest of Western Australia in the mid-20th century. This reduced inflows to the Perth water supply by about 120 GL (42\%) and led to an acceleration of projects to develop new water sources at a cost of about $\$ 300$ million. The reduction in rainfall was coincident with warmer temperatures. A major analysis of these changes indicated that the changes in temperature were likely caused by the enhanced greenhouse effect and that the changes in rainfall were likely caused by a large-scale reorganization of the atmospheric circulation. We explore an alternative hypothesis that large-scale land cover change explains the observed changes in rainfall and temperature. We use three high-resolution mesoscale model configurations forced at the boundaries to simulate (for each model) five July climates for each of natural and current land cover. We find that land cover change explains up to $50 \%$ of the observed warming. Following land cover change, we also find, in every simulation, a reduction in rainfall over southwest Western Australia and an increase in rainfall inland that matches the observations well. We show that the reduced surface roughness following land cover change largely explains the simulated changes in rainfall by increasing moisture divergence over southwest Western Australia and increasing moisture convergence inland. Increased horizontal wind magnitudes and suppressed vertical velocities over southwest Western Australia reduce the likelihood of precipitation. Inland, moisture convergence and increased vertical velocities lead to an increase in rainfall. Our results indicate that rainfall over southwest Western Australia may be returned to the long-term average through large-scale reforestation, a policy option within the control of local government. Such a program would also provide a century-scale carbon sink to ameliorate Australia's very high per capita greenhouse gas emissions. INDEX TERMS: 1655 Global Change: Water cycles (1836); 3322 Meteorology and Atmospheric Dynamics: Land/atmosphere interactions; 3329

Meteorology and Atmospheric Dynamics: Mesoscale meteorology; KEYWORDS: land cover change, mesoscale modeling, regional climate change

Citation: Pitman, A. J., G. T. Narisma, R. A. Pielke Sr., and N. J. Holbrook (2004), Impact of land cover change on the climate of southwest Western Australia, J. Geophys. Res., 109, D18109, doi:10.1029/2003JD004347.

\section{Introduction}

[2] A key issue in Australian climate is the substantial decrease in winter rainfall in the southwest of Western Australia (SWWA, defined as southwest of a line connecting $30^{\circ} \mathrm{S}, 115^{\circ} \mathrm{E}$ and $35^{\circ} \mathrm{S}, 120^{\circ} \mathrm{E}$, Figure 1a). This decline has occurred since the mid-20th century and is particularly clear in early winter (May-July) rainfall [Indian Ocean Climate Initiative (IOCI), 2002]. Winter rainfall suddenly decreased in the mid-1970s by about $15-20 \%$, a change

Copyright 2004 by the American Geophysical Union. 0148-0227/04/2003JD004347\$09.00 described by the IOCI [2002] as a switch to an alternative rainfall regime. This winter rainfall reduction led to reduced streamflow, warmer daytime and warmer nighttime temperatures. The acceleration of projects to develop new water sources to adapt to the lower rainfall is estimated to have cost AU $\$ 500$ million (about $\$ 300$ million) following the reduction of $120 \mathrm{GL}$ (about 42\%) inflow into the Perth water supply [IOCI, 2002].

[3] The climate of southwest Western Australia is dominated by winter rainfall [Wright, 1997]. A gradient in winter rainfall occurs from east to west and a temperature gradient exists from south to north. Winter rainfall is associated with moist unstable westerly winds and with 


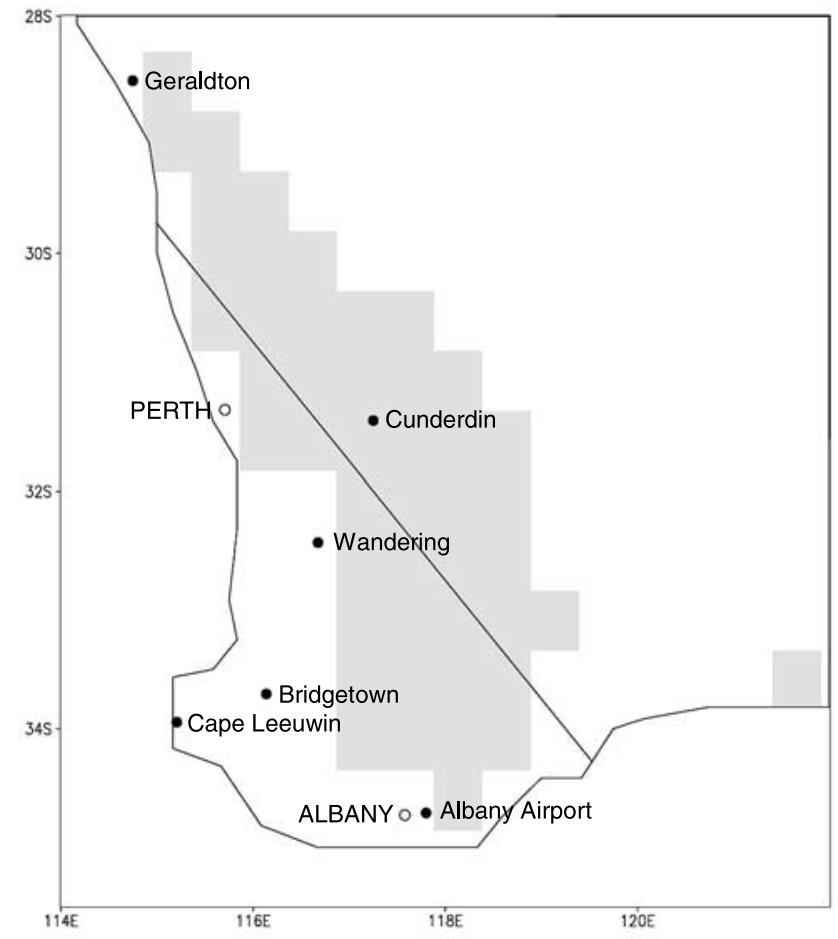

Figure 1a. Locations of land cover change (trees to grass or crops between 1788 and 1988) over Western Australia using the AUSLIG [1990] vegetation mapping. Observed stations are shown in solid circles. The region of SWWA is southeast of the diagonal line.

progressive troughs within the predominantly westerly airstream. The mean depression tracks and the associated zones of maximum rainfall are to the south of the region, accounting for the rainfall gradient from south to north. Farther eastward, the rainfall declines with distance from the coast. The concentration of the observed rainfall decrease in May-July, the time of year when rainfall is most often associated with winds from the northwest and northwest cloudbands, suggests that the decrease in rainfall may have been associated with a decrease in the frequency, intensity, or preferred track of these cloudbands, or their interactions with cold fronts and midlatitude depressions [IOCI, 2002].

[4] Given the processes that cause winter rainfall in SWWA the IOCI [2002], in the only thorough analysis of the observed change, associate the sudden reduction in winter rainfall in the mid-1970s with a change in the large-scale global atmospheric circulation. The sudden drop in winter rainfall was coincident with an increase in atmospheric pressure and a drop in the southern oscillation index [Smith et al., 2000]. Simmonds and Keay [2000] identified a decline in the frequency and intensity of synoptic depressions affecting the region over the last 40 years. These support a large-scale change in the atmospheric circulation as an explanation for the rainfall decline [IOCI, 2002]. IOCI [2002] also comment that there may be some association between the enhanced greenhouse effect and the decrease in rainfall, and they express some confidence that the observed 20th century warming over SWWA is attributable to the enhanced greenhouse effect. The IOCI [2002] comment on other possible factors that may explain the changes in rainfall, noting that the extensive land-use changes that have taken place since European settlement in the 18th century seem unlikely to explain the rainfall decrease, but may be secondary contributors. They suggest that more modeling should be undertaken to assess the possible impacts of local land-use change on the regional climate.

[5] Narisma and Pitman [2003] explored the impact of continental-scale land cover change (LCC) on the Australian climate. They used a high-resolution regional climate model (MM5, see section 2.1) at a $50 \mathrm{~km}$ grid spacing forced by boundary conditions from the National Center for Environmental Prediction (NCEP; Kalnay et al. [1996]) and LCC data reflecting natural vegetation cover and cover representing 1988 [Australian Surveying and Land Information Group (AUSLIG), 1990]. Narisma and Pitman [2003] were building on earlier work using models to explore the impact of LCC. Much of this work has explored the impact of continental-scale tropical deforestation [Henderson-Sellers et al., 1993; Kanae et al., 2001] but it has also addressed the impact of boreal forest changes [Bonan et al., 1992], the impact of agriculture [Marshall et al., 2003], urbanization [Kalnay and Cai, 2003] etc. It is now recognized that large-scale LCC can have a significant effect on regional climate [e.g., Pielke et al., 1998; Pielke, 2001]. At the regional-scale LCC is an important anthropogenic forcing [Houghton et al., 2001] that can be as significant as increasing carbon dioxide $\left(\mathrm{CO}_{2}\right)$ concentrations [Pielke, 2001].

[6] The impact of LCC on the micrometeorology of SWWA has been explored before [Lyons et al., 1993; Huang et al., 1995; Lyons et al., 1996; Lyons, 2002; Ray et al., 2003] where changes in the regional meteorology have been linked to LCC using observations and modeling. While this work has usually focused on timescales of a few
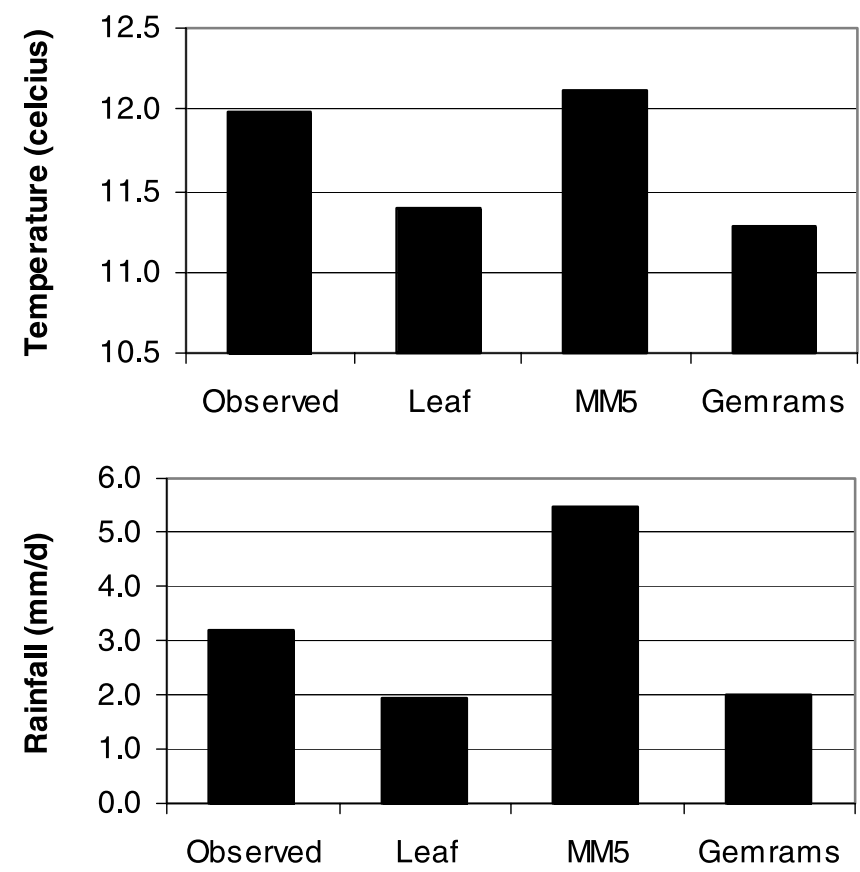

Figure 1b. The observed and simulated temperature and rainfall from each model configuration. 

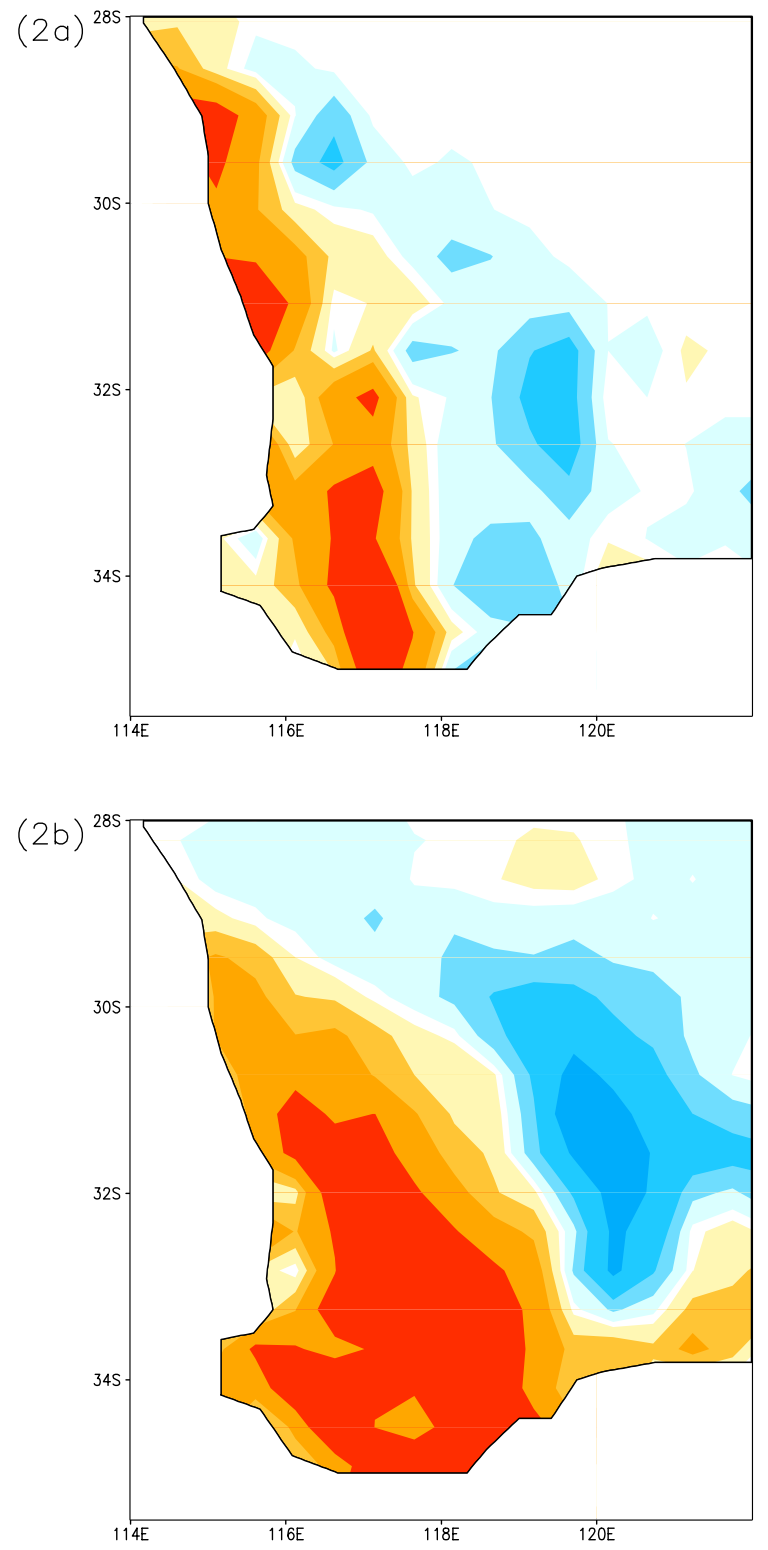

(2c)

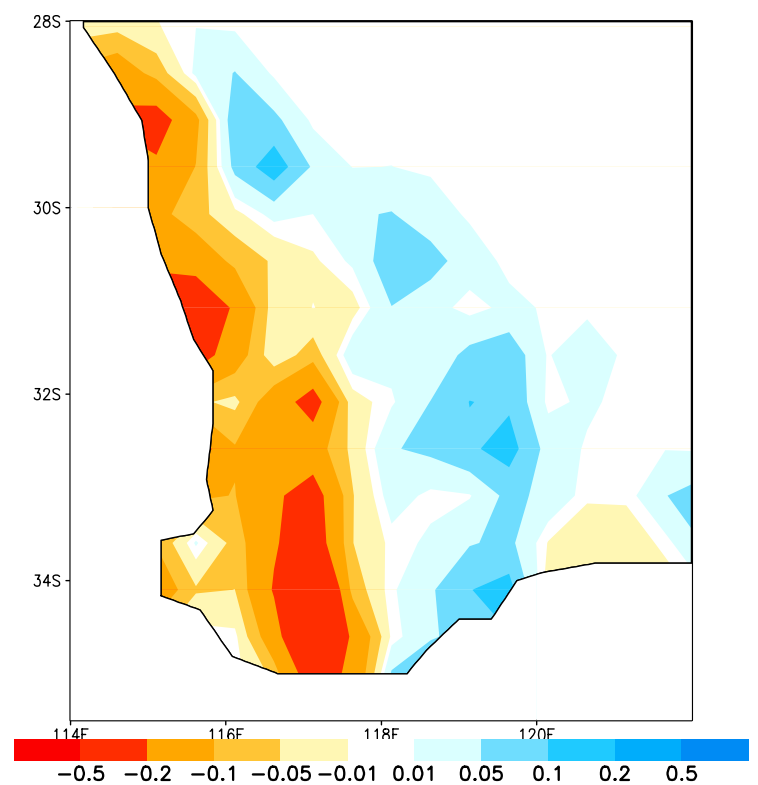

days it does hint that larger timescale impacts on weather and climate may follow LCC. Ray et al. [2003], for example, find observed changes in cloudiness associated with changes in sensible heat fluxes over regions of LCC in SWWA. Unfortunately, their analyses do not highlight the processes operating in May through July (the period of observed rainfall decline). We are therefore left in a dichotomy with IOCI [2002] assessing the role of LCC in reducing rainfall over SWWA as limited, while an extensive literature suggests that LCC can affect regional climates. In this paper we explore the significance of large-scale LCC on the July climatology of SWWA.

\section{Methodology}

[7] Since results from a single regional climate model may be model-dependent, we use three model configurations and boundary conditions from five different July realizations of the large-scale meteorology of SWWA. In all simulations the models are initialized with boundary conditions taken from the NCEP Global Data Assimilation System analysis [Kalnay et al., 1996]. A total of 10 simulations are performed for each of MM5 (section 2.1), LRAMS (section 2.2.1) and GEMRAMS (section 2.2.2) consisting of boundary conditions from five different Julys (1986, 1988, 1989, 1990, and 1994). This large ensemble of experiments, which includes "average" years as well as years representative of La Nina and El Nino conditions, allow us to explore whether the impact of LCC is consistent through varying meteorological conditions.

[8] Vegetation data are obtained from the Atlas of Australian Resources on Vegetation by the Australian Surveying and Land Information Group [AUSLIG, 1990] mapped onto the vegetation classifications used in the models [see Narisma and Pitman, 2003]. The AUSLIG [1990] data provide natural vegetation cover (prior to European settlement in 1788) and cover representative of 1988. Figure 1a shows that there has been a significant loss of tree cover in Western Australia with a conversion of wet sclerophyll and dry sclerophyll forest to grass and agricultural crops. This is a consequence of the European settlement in the late 1700s and early 1800 s which introduced widespread livestock grazing in Australia $[A U S L I G, 1990]$ and led to a minimum modification of around $32 \%$ of the vegetation, a modification described by Williams [2003] as "brutal." Most of the land clearance occurred between 1920 and 1980.

\subsection{MM5}

[9] We use the fifth-generation NCAR/PSU mesoscale model (MM5) as described by Grell et al. [1994] coupled with a surface model described by Xiu and Pleim [2001]. MM5 has been widely used for weather and climate modeling and was used by Narisma and Pitman [2003] to explore the impact of LCC over Australia. MM5's land model has been shown to simulate soil moisture conditions and evaporation well, and to model seasonal trends in deep

Figure 2. The simulated change in rainfall caused by land cover change over Western Australia. Reductions in rainfall are shaded. (a) GEMRAMS, (b) MM5, and c) LRAMS. Shading intervals are in $\mathrm{mm} \mathrm{d}^{-1}$. 

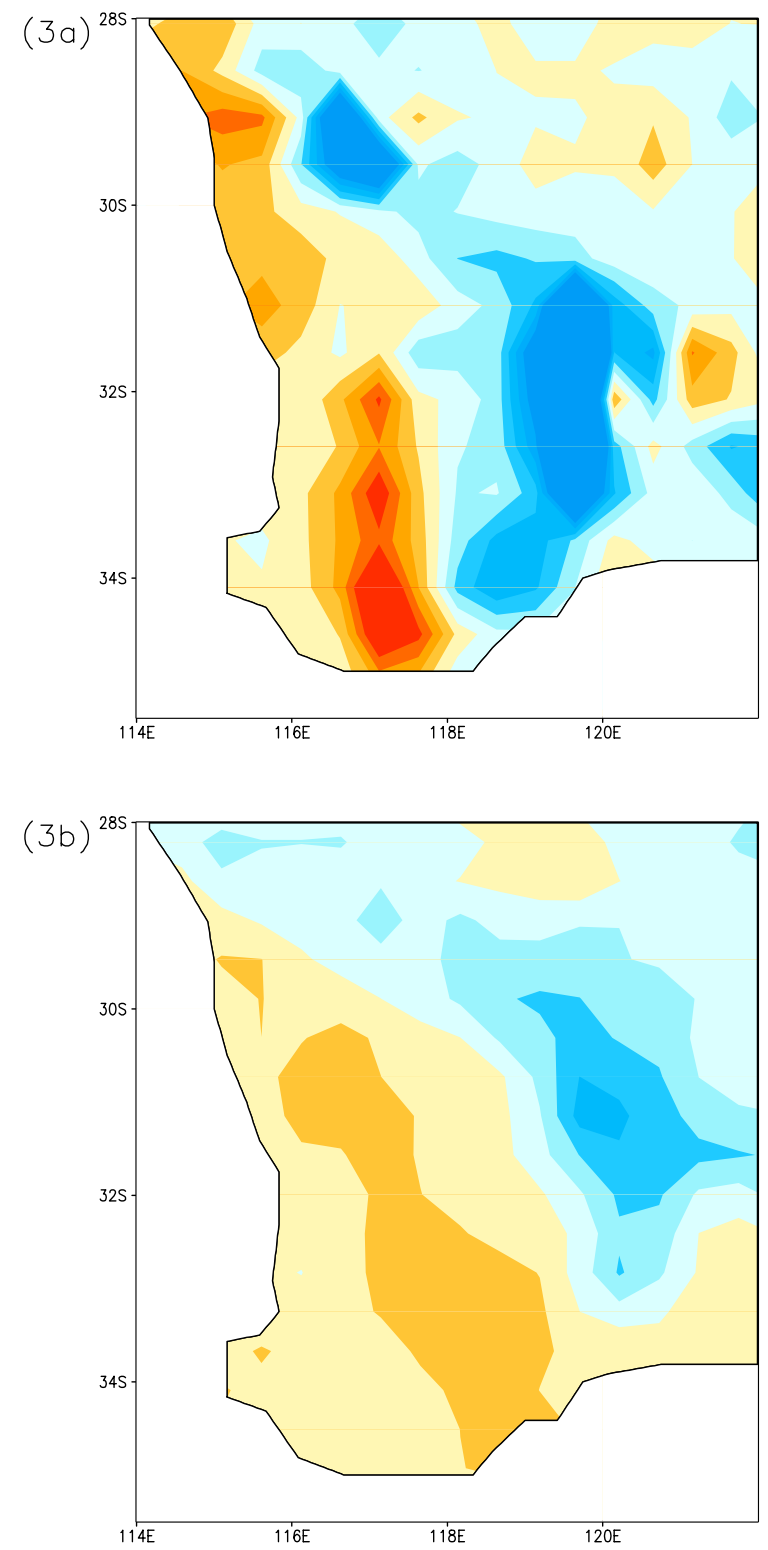

(3c)

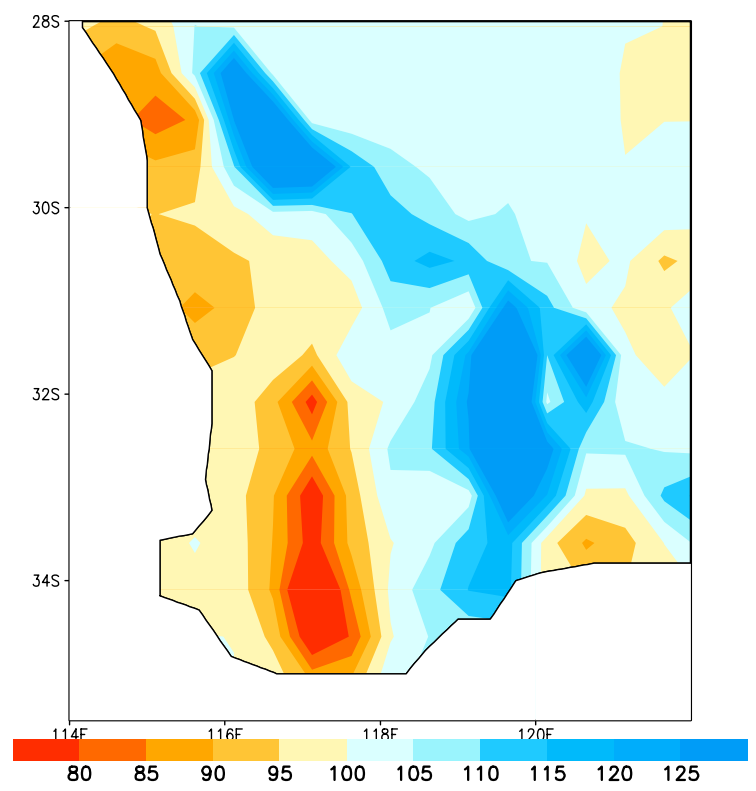

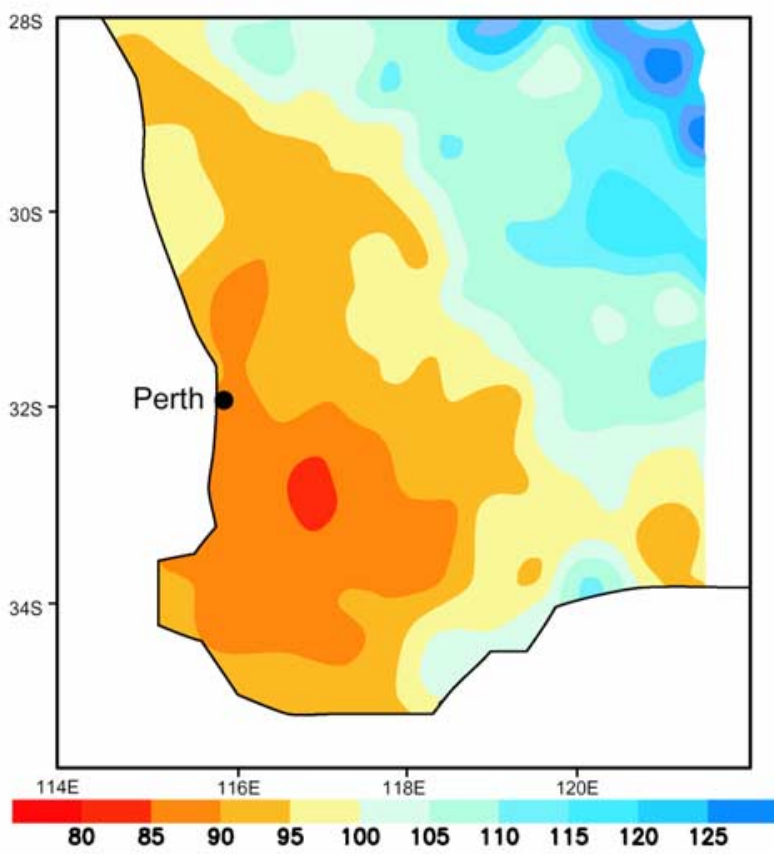

Figure 4. The observed percentage change in rainfall (average of 1976-2001 compared to average of 19251975) [after IOCI, 2002]. Colored intervals are shown as percentages.

soil temperature, surface fluxes, and surface air temperature adequately [Xiu and Pleim, 2001].

[10] The MM5 is applied at a $50-\mathrm{km}$ horizontal grid spacing, $60 \times 87$ grid domain, covering most of Australia. MM5 incorporates simple ice microphysics [Dudhia, 1989], cloud interactive radiation [Dudhia, 1989], a convective scheme based on Grell et al. [1994], and a boundary layer scheme based on Xiu and Pleim [2001]. The control simulation (1988 land cover) simulates an average temperature over the continental surface shown in Figure 1a of $12.1^{\circ} \mathrm{C}$ and a precipitation rate of $5.47 \mathrm{~mm} \mathrm{~d}^{-1}$ (Figure $1 \mathrm{~b}$ ). This compares with $12.0^{\circ} \mathrm{C}$ and $3.17 \mathrm{~mm} \mathrm{~d}^{-1}$ (observed, Figure $1 \mathrm{~b}$ ). Thus the simulation of temperature is excellent, but the model over-predicts rainfall. However, note that the observations are averages over the stations shown in Figure 1a while the model results are area averages, hence the significance of similarities or differences should be interpreted with care.

\subsection{RAMS}

[11] We also performed LCC experiments using the Colorado State University Regional Atmospheric Modeling System (RAMS; Cotton et al. [2003]). RAMS is a flexible meteorological modeling system that has been extensively used to study the impact of LCC on weather and climate

Figure 3. The percentage change in rainfall (rainfall under current vegetation as a percentage of rainfall under natural vegetation) over Western Australia. Reductions in rainfall are shaded. (a) GEMRAMS, (b) MM5, and (c) LRAMS. Shaded intervals are shown as percentages. 
[see Pielke et al., 1998]. All RAMS simulations used the Kain and Fritsch [1993] convection scheme and the Chen and Cotton [1987] short-wave and long-wave radiation schemes. Using RAMS, we performed simulations for a large domain $\left(108^{\circ} \mathrm{E}\right.$ to $128^{\circ} \mathrm{E}$ and $25^{\circ} \mathrm{S}$ to $\left.40^{\circ} \mathrm{S}\right)$ at a $56-\mathrm{km}$ grid spacing. We used, therefore, 80 latitude and 100 longitude grids, combined with 30 vertical atmospheric levels and 15 soil layers. The domain was large enough to ensure that any boundary condition problems at the edge of the domain did not affect the simulations over the continental areas.

[12] To minimize the likelihood that our results would be dependent on the land model used, two philosophically different parameterizations were coupled to RAMS: one that includes the biophysics (a second generation land model; see Sellers et al. [1997]) and one that includes the biospheric response to changes in the atmospheric forcing (a third generation model; see Sellers et al. [1997]). These two land models are briefly described below.

\subsubsection{RAMS and LEAF-2 (LRAMS)}

[13] We used RAMS coupled to LEAF-2 (LRAMS). LEAF-2 represents the energy and moisture budgets for the soil and vegetation and the exchange of this energy and moisture with the atmosphere [Walko et al., 2000]. It simulates soil moisture and soil temperature, vegetation temperature and surface water (including dew and intercepted rainfall). LEAF-2 simulates the exchange of radiative and turbulent terms energy fluxes [Walko et al., 2000]. The grid element is divided horizontally into patches, allowing multiple surface types to coexist under a single gridresolved atmospheric column. Interception of rainfall is parameterized and a multilayer soil model simulates the vertical transfer of soil water. Evaporation from soil and wet leaves and transpiration from dry leaves are evaluated separately. Further information can be found in the work of Walko et al. [2000] and at http://rams.atmos.colostate. edu/.

[14] The control version of LRAMS (1988 land cover) simulates a July average temperature of $11.4^{\circ} \mathrm{C}\left(0.6^{\circ} \mathrm{C}\right.$ cooler than the observed, Figure $1 \mathrm{~b}$ ). It simulates a rainfall rate of $1.97 \mathrm{~mm} \mathrm{~d}^{-1}$ which is lower than the observed rate of $3.17 \mathrm{~mm} \mathrm{~d}^{-1}$ (Figure 1b).

\subsubsection{RAMS and GEMTM (GEMRAMS)}

[15] We also used RAMS coupled to GEMTM, a plant model that simulates the dynamic interaction between the biosphere and atmosphere [Chen and Coughenor, 1994]. This coupled model (GEMRAMS) allows the vegetation to respond to changes in $\mathrm{CO}_{2}$ concentration and climate. At each time step, GEMTM calculates stomatal conductance as a function of relative humidity and $\mathrm{CO}_{2}$ concentration [Chen and Coughenor, 1994]. The photosynthetic rate is dependent on the atmospheric $\mathrm{CO}_{2}$ and vegetation temperature as well as on the photosynthetically active radiation and plant water potential. The control version of GEMRAMS (1988 land cover) simulates a July average temperature of $11.3^{\circ} \mathrm{C}$ and a rainfall rate of $2.01 \mathrm{~mm} \mathrm{~d}^{-1}$ (overall slightly superior to LRAMS but still lower than observed, Figure 1b).

Figure 5. As Figure 2 but for the latent heat flux. Contour intervals are shown at $-5,-10$, and $-30 \mathrm{~W} \mathrm{~m}^{-2}$.
$(5 a)$

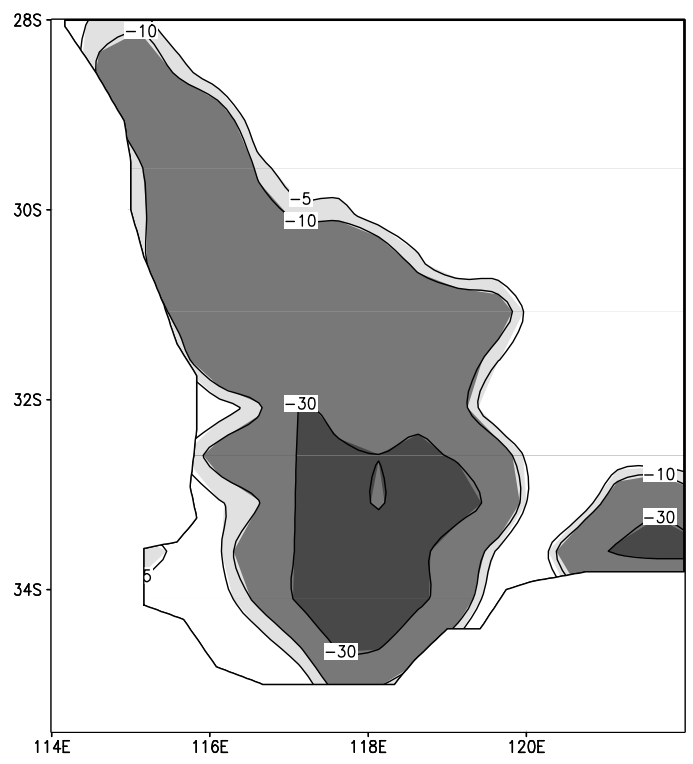

(5b)

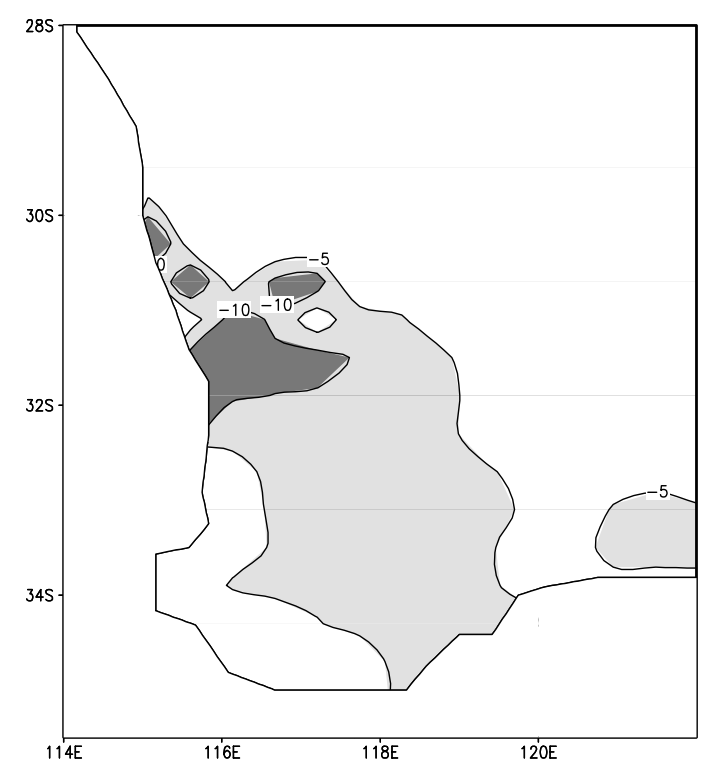

(5c)

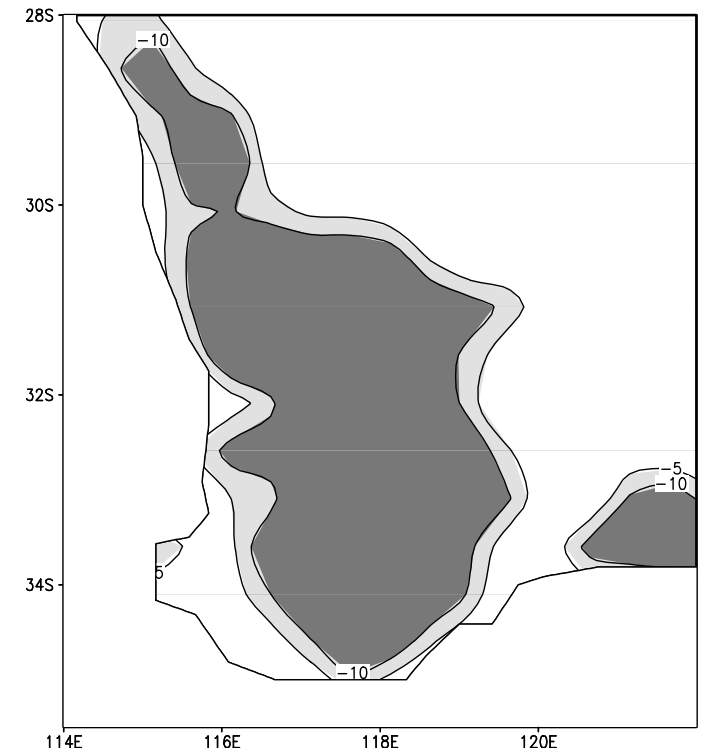


(6a)

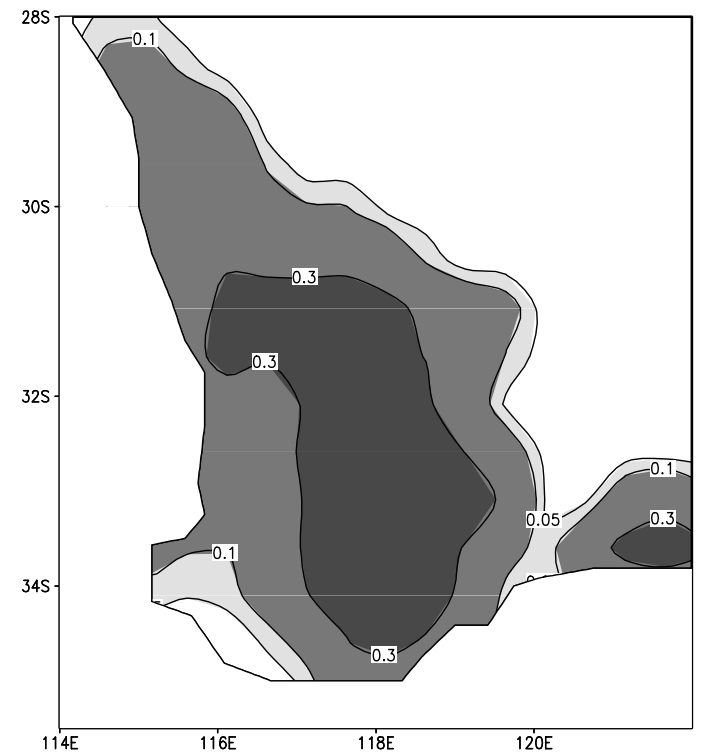

(6b)

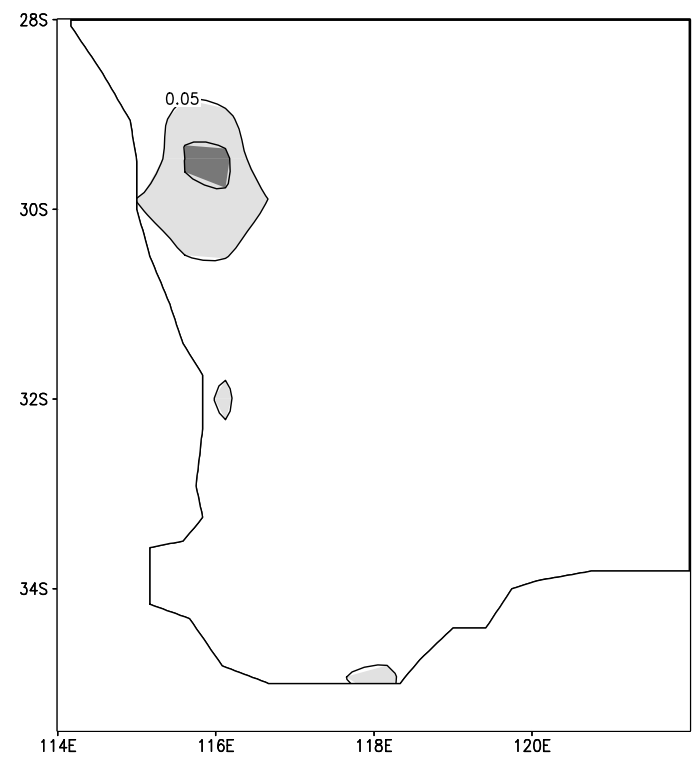

(6c)

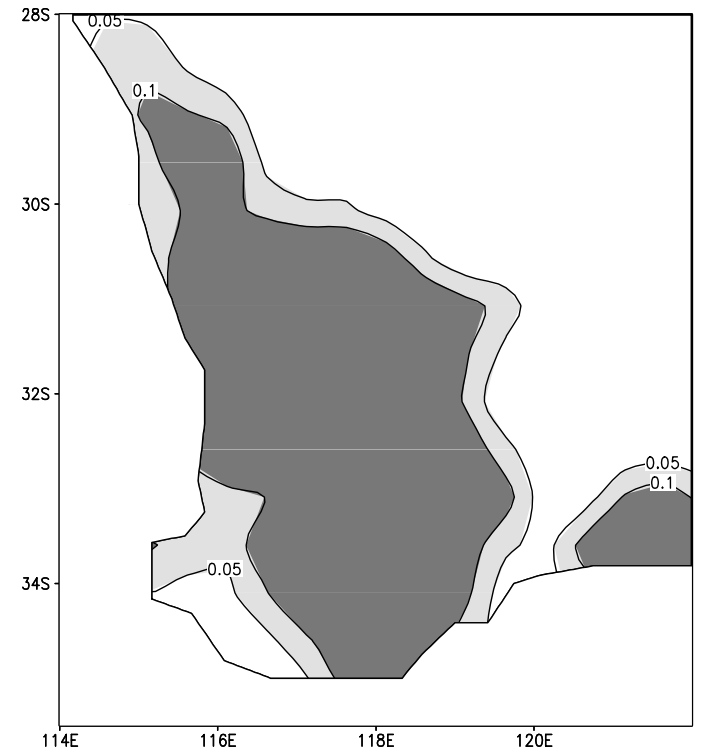

[16] Overall therefore, the three model configurations bracket the observed estimates of precipitation (MM5 simulating too much and LRAMS and GEMRAMS simulating too little). MM5 has an excellent simulation of temperature while LRAMS and GEMRAMS are marginally too cool. We also ran LRAMS for the same domain at $20 \mathrm{~km}$ grid intervals. The results were noisier, but changes due to LCC were consistent with those produced at $56 \mathrm{~km}$ resolution.

\section{Results}

[17] Simulated impacts following LCC are caused by modifications to the vegetation characteristics. Converting from trees to grass, for example, typically reduces leaf area index (LAI), increases albedo, decreases roughness length and the zero plane displacement height, alters root distribution and depth and affects stomatal conductance [e.g., Sellers, 1992]. These changes affect the partitioning of available water between runoff and evaporation, thereby affecting soil moisture and possibly rainfall. Further, these changes affect the partitioning of available energy between sensible and latent heat, affecting local air temperature and boundary layer structure [Lyons, 2002]. Changes in roughness length or the zero plane displacement height may also affect wind patterns [Kanae et al., 2001] and turbulence.

[18] Figure 2 shows the impact of LCC on simulated rainfall. In all models, there is a reduction in rainfall in SWWA and an increase in rainfall further inland. The decrease near the coast is approximately $0.1-0.3 \mathrm{~mm} \mathrm{~d}^{-1}$ with increases inland of up to $0.5 \mathrm{~mm} \mathrm{~d}^{-1}$ in all models (Figure 2). Expressed in percentage terms, these simulated changes are $10-20 \%$ of the total rainfall simulated under natural vegetation cover (Figure 3). We emphasize that all individual ensembles for each model configuration shows this pattern, thus this result is independent of any single model framework and independent of the specific boundary conditions.

[19] The observed changes in rainfall, reported by IOCI [2002] are shown in Figure 4. The noteworthy observed change is a reduction in rainfall over SWWA of $10-15 \%$ (average of 1976-2001 compared to average of 1925$1975 ;$ IOCI [2002]) and an increase inland of $10-20 \%$. The models capture the reduction in rainfall over SWWA and captures the increase in rainfall inland. Along the southern coast, LRAMS and GEMRAMS even capture the pattern of reduced rainfall around $117^{\circ} \mathrm{E}$, alternating to an increase in rainfall around $119^{\circ} \mathrm{E}$ and then a second area of reduced rainfall at about $121^{\circ} \mathrm{E}$. While the geographical detail varies between the three model configurations, overall the simulated changes are very similar to the observed. Long-term observational data for precipitation are rather sparse in this region. The decline in precipitation over the stations shown in Figure 1a (expressed as a decline in the 19762001 average from the $1925-1975$ average) is $14 \%$ $\left(-0.50 \mathrm{~mm} \mathrm{~d}^{-1}\right)$. In GEMRAMS and LRAMS a decline of $6 \%$ is simulated $\left(-0.11 \mathrm{~mm} \mathrm{~d}^{-1}\right)$ while in MM5 a $4 \%$

Figure 6. As Figure 2 but for near surface air temperature. Contour intervals are shown at $0.05,0.1$, and $0.3^{\circ} \mathrm{C}$ and are shaded to ease comparison with Figure 5. 
$(7 a)$

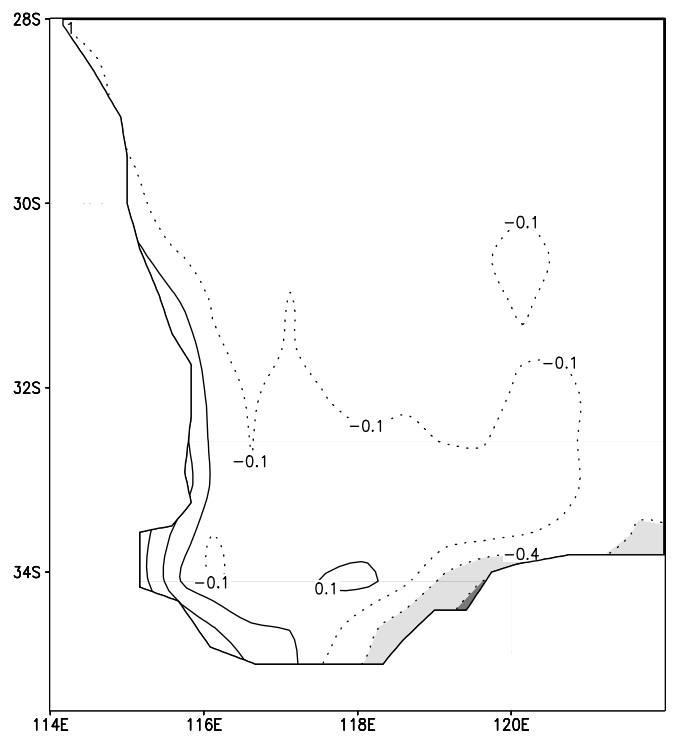

(7c)

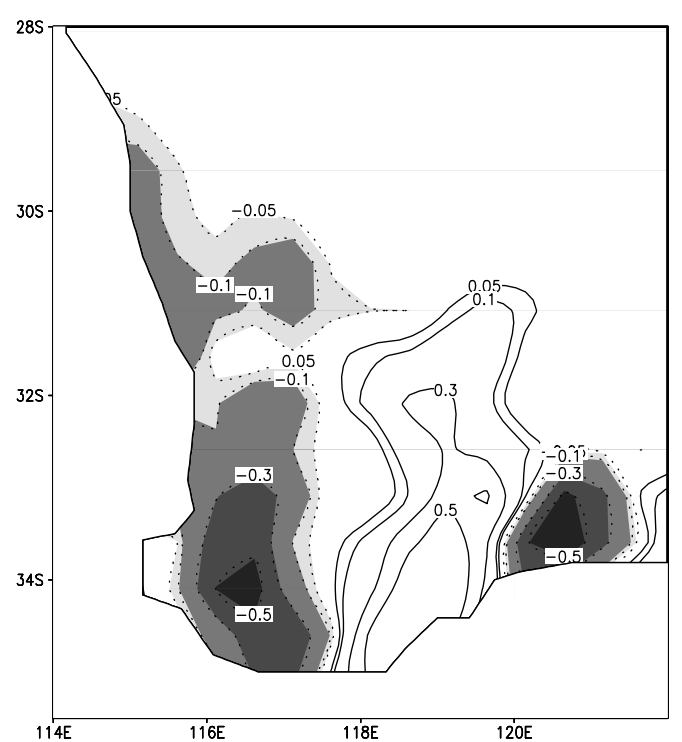

(7b)

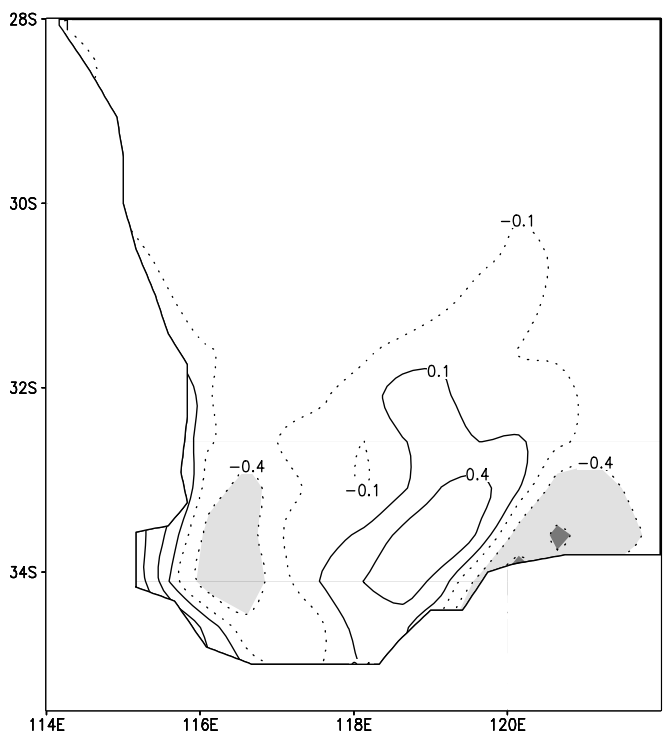

$(7 d)$

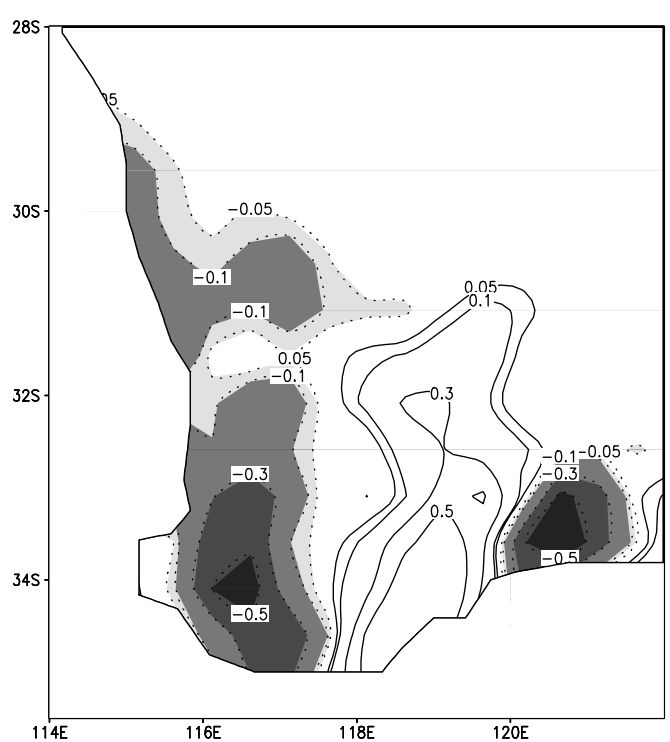

Figure 7. (a) Moisture convergence simulated by LRAMS for natural vegetation cover. (b) Moisture convergence simulated by LRAMS for current vegetation cover. (c) Difference in moisture convergence simulated by GEMRAMS (current minus natural). (d) Difference in moisture convergence simulated by LRAMS (current minus natural). Contour intervals are shown at $-5,-10$, and $-30 \mathrm{~kg}^{-1} \mathrm{~s}^{-1}$.

reduction is simulated $\left(-0.21 \mathrm{~mm} \mathrm{~d}^{-1}\right)$. This agreement would appear quite reasonable given that our simulations are just for July and reductions that occur in June that affect soil moisture are not captured in our simulations. At the very least, these results suggest that LCC plays a significant role in moderating the precipitation in the region. Unfortunately we were unable to source longterm station-based observational data for the areas of precipitation increase shown in Figure 4.

\section{Mechanisms That Do and Do Not Explain the Changes in Rainfall}

[20] The primary impact of LCC is most likely to be seen in the partitioning of available energy between sensible and latent heat fluxes (since many of the biophysical parameter changes directly affect the accessibility of the vegetation to water, or the ability of the vegetation to transpire water). The LCCs observed over Western Australia are known to have affected this partitioning, as well as boundary layer structure and cloud amounts [Lyons, 2002; Ray et al., 2003]. Figure 5 shows a systematic reduction in the latent heat flux simulated by GEMRAMS $\left(10-30 \mathrm{~W} \mathrm{~m}^{-2}\right)$, MM5 $(5-$ $\left.10 \mathrm{~W} \mathrm{~m}^{-2}\right)$ and LRAMS $\left(5-10 \mathrm{~W} \mathrm{~m}^{-2}\right)$. This reduction is clear in each individual ensemble of each model experiment (not shown) and the patterns of latent heat reduction match the areas of LCC (Figure 1a) closely. The change in the latent heat flux in MM5 is relatively smaller than the two versions of RAMS and does not lead to a noticeable change in average temperature (Figure 6b). However, in LRAMS, temperature increases over SWWA by $0.1{ }^{\circ} \mathrm{C}$ and in GEMTM it increases by up to $0.3^{\circ} \mathrm{C}$ (Figure 6a). Using 
(8a)

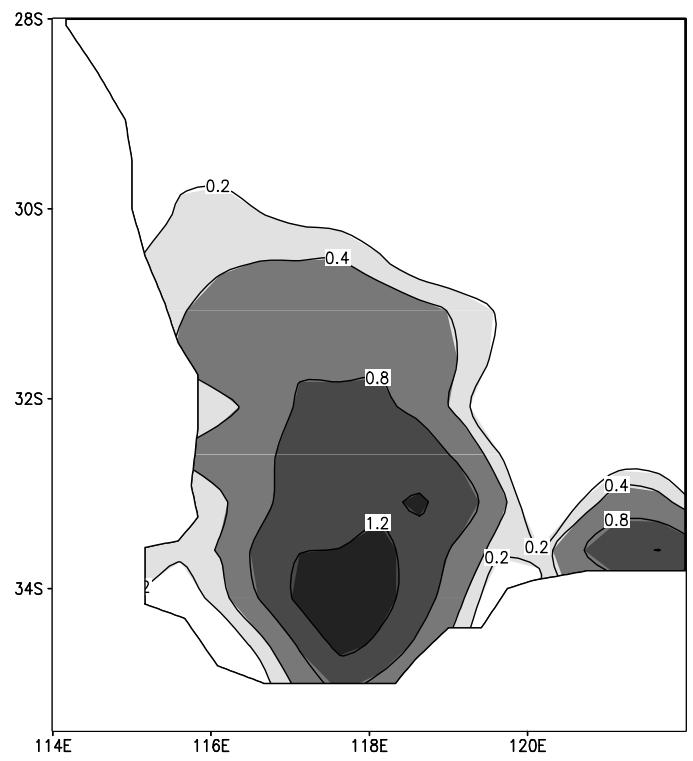

(8b)

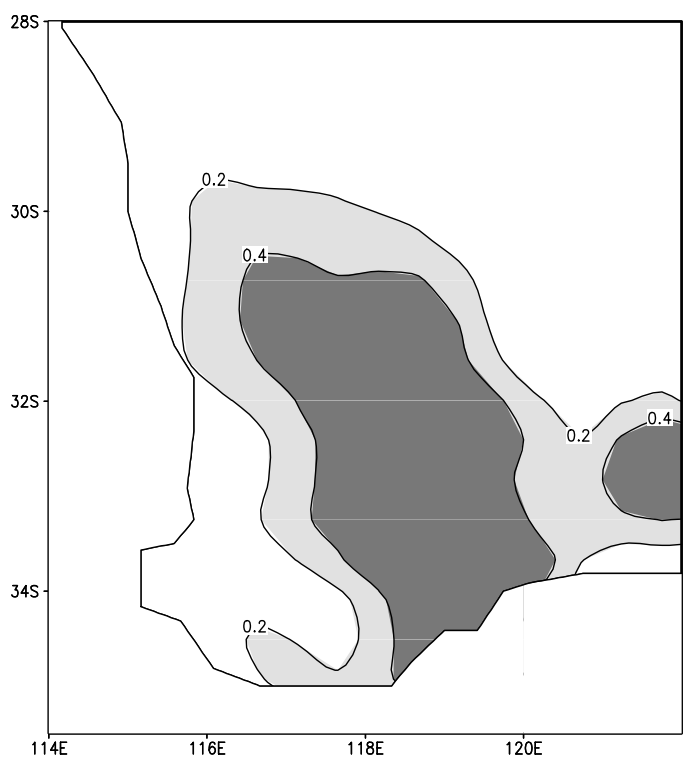

$(8 c)$

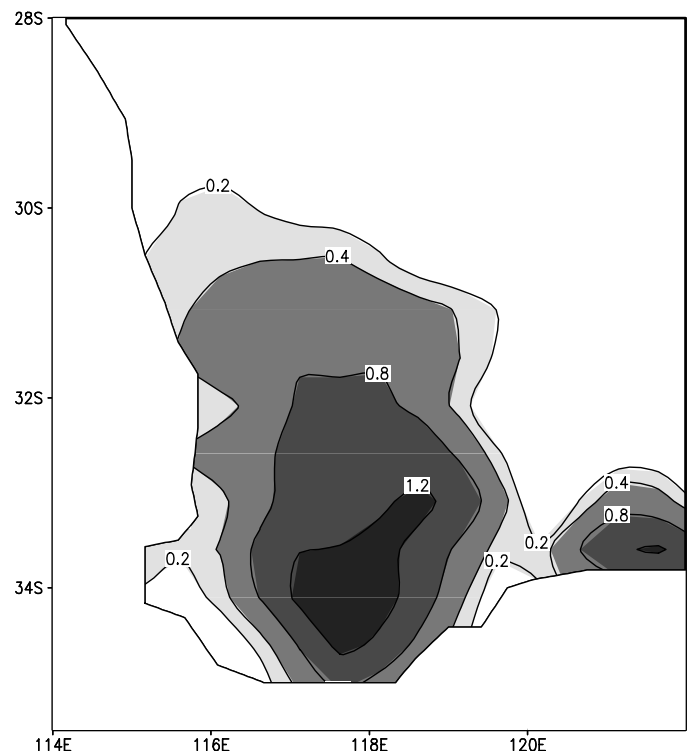

the observational data from the stations shown in Figure 1a, the observed temperature has warmed in this region by $0.44^{\circ} \mathrm{C}$. In LRAMS and GEMTM the warming is $0.12^{\circ} \mathrm{C}$ and $0.22^{\circ} \mathrm{C}$ respectively. We therefore conclude that a significant fraction of the observed warming over SWWA may be due to LCC.

[21] These changes in the latent heat flux and temperature, while potentially important to agriculture, do not explain the simulated changes in precipitation. The latent heat flux is systematically reduced in GEMRAMS and LRAMS over regions where precipitation both decreases $\left(117^{\circ} \mathrm{E}\right)$ and increases $\left(119^{\circ} \mathrm{E}\right)$ (compare Figures $5 \mathrm{c}$ and $2 \mathrm{c}$ for example). In the two versions of RAMS, rainfall declines west of and increases to the east of $118^{\circ} \mathrm{E}$ but the pattern of LCC (Figure 1a) is almost centered on $118^{\circ} \mathrm{E}$. We therefore need a mechanism whereby a common LCC can locally explain both a decrease and an increase in precipitation. Clearly a single column-based explanation of a change in the surface energy balance leading to local changes in moisture availability, or a local change in sensible heating connecting through the boundary layer to changes in convection and precipitation cannot explain our modeled results.

[22] Figure 7 shows moisture convergence at the first model layer $(48 \mathrm{~m})$ (similar patterns are duplicated at model layers $2(155 \mathrm{~m})$ and $3(280 \mathrm{~m})$. Figure $7 \mathrm{a}$ shows a homogeneous pattern of moisture convergence for natural vegetation (for GEMRAMS, similar results were obtained with LRAMS and MM5). Figure $7 \mathrm{~b}$ shows the same quantity for current vegetation, demonstrating that LCC has led to the development of strong heterogeneity in the moisture convergence pattern. The difference (GEMRAMS, Figure 7c; LRAMS, Figure 7d) shows increased divergence near the coast and increased convergence further inland. There is a striking similarity between the patterns of moisture convergence change and precipitation change. The pattern of change in the magnitude of the horizontal winds (at $48 \mathrm{~m}$ ) explains the moisture divergence near the coast and the transport of moisture inland (Figure 8). There is also an associated change, with reduced vertical velocities over the regions of LCC and, as a result of the reduced roughness in these regions and the increased surface wind speeds, a pattern of increasing vertical velocities inland (Figure 9). In general, the changes in moisture convergence (Figure 7), combined with the changes in vertical velocities (Figure 9) explain the changes in precipitation (Figure 2). The regions where vertical velocities increase coincides with increased moisture convergence and these combine to increase the tendency for precipitation.

[23] We explored this mechanism further by conducting two additional experiments with LRAMS. In the first experiment, only the surface roughness and zero plane displacement height were changed in the regions of LCC. In the second experiment only LAI, root depth, minimum stomatal conductance and vegetation fraction were changed. These experiments therefore isolate the roughness parameters from those that control moisture exchange. Figure 10

Figure 8. As Figure 2 but for the horizontal surface wind magnitude. Contour intervals are shown at $0.2,0.4,0.8$, and $1.2 \mathrm{~m} \mathrm{~s}^{-1}$. 


\section{(9a)}

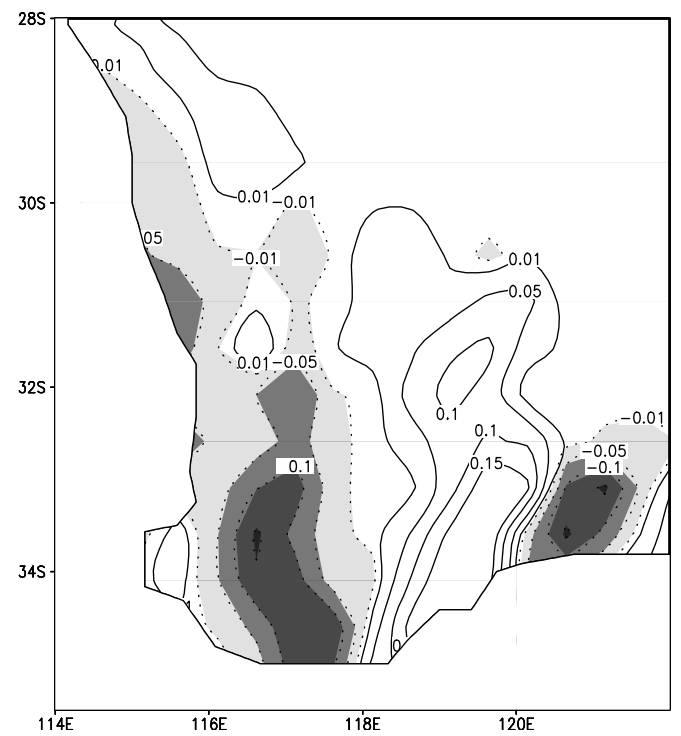

(9b)

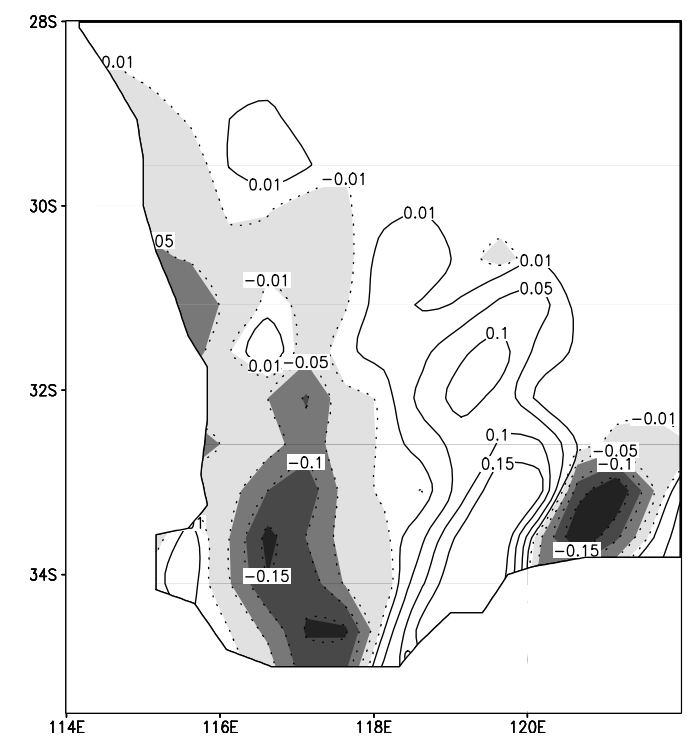

Figure 9. As Figure 2 but for vertical velocity (at $280 \mathrm{~m}$ ): (a) GEMRAMS. (b) LRAMS. Contour intervals are shown at $\pm 0.01,0.05,0.1$, and $0.15 \mathrm{~m} \mathrm{~s}^{-1} \times 100$.

shows the impact of these two sets of changes on the moisture convergence (Figures 10a and 10b), vertical velocities (Figures 10c and 10d) and precipitation (Figures 10e and 10f). The roughness length and zero plane displacement parameters lead to an overall pattern of changes that are quite similar to the combined results (i.e., Figure 10e is very similar to Figure 2c, but Figure 10f is not similar to Figure 2c). Figure 11 shows the percentage of the control precipitation changes (Figure 2c) that occur through just the change in the roughness parameters (Figure 11a) and through just the change in the moisture exchange parameters (Figure 11b). Over most of the region, the changes in the roughness parameters alone explain $80-$ $100 \%$ of the simulated change in precipitation (Figure 11a) while the moisture exchange parameters explain a small fraction of the total change $(0-20 \%)$, where this change is significantly different from zero. Thus, overall, the changes in the parameters that control the moisture exchange and the latent heat flux explain little of the overall impact of LCC on precipitation in this region. Rather the changes in precipitation are caused by the modification to the surface roughness parameters. The sensitivity in rainfall to the roughness parameters is not apparent elsewhere over the continent. Narisma and Pitman [2003, Figure 3d] show that changes in land cover have a negligible and nonstatistically significant effect on rainfall in July in continental-scale simulations except over Western Australia. It is the combination of the roughness change and local onshore winds over Western Australia that generates the sensitivity of rainfall to roughness shown in Figure 11a.

\section{Discussion and Conclusion}

[24] The conclusion of the most detailed analysis of the cause of the changes in climate over SWWA concluded that the decline in rainfall in this region was associated with a change in the large-scale atmospheric circulation, and that the warming in this region was associated with the enhanced greenhouse effect $[I O C I, 2002]$. This paper presents evi- dence that LCC over SWWA has also contributed significantly to the observed changes in precipitation and temperature.

[25] The change in precipitation caused by LCC simulated through multiple ensembles of three modeling frameworks is similar to the observed changes in terms of both magnitude and pattern. While the observed and modeled patterns of precipitation change differ in detail, the percentage change in simulated rainfall (Figure 3 ) is very similar to the observed (Figure 4) in terms of pattern and size. Given that we used three modeling frameworks and five July simulations for each model experiment, and the changes simulated for precipitation are consistent for every individual July realization, it is extremely unlikely that this simulated pattern matches the observed pattern by coincidence. Since we did not vary sea surface temperatures, carbon dioxide or the lateral boundary conditions between the simulations using current and natural land cover, the changes we simulate cannot be explained in these terms. We also repeated these experiments with LRAMS at a $20-\mathrm{km}$ resolution and obtained a similar result.

[26] The changes in observed temperature over SWWA were suggested by IOCI [2002] to be associated with the enhanced greenhouse effect. The three models differ in their estimate of the simulated warming ranging between no warming (MM5), to $50 \%$ of the observed warming (GEMRAMS). Since we are simulating isolated months (July) we cannot capture trends in soil moisture associated with drying in June, and we therefore probably underestimate the large-scale impact of LCC on the latent heat flux and temperature. We suspect therefore that the warming simulated by the three models are underestimates, but longer simulations would be required to address this issue. Irrespective of this, LRAMS (27\%) and GEMRAMS (50\%) capture enough of the observed warming to be an important component of any detection and attribution studies.

[27] In our analysis of the reasons why LCC led to the changes in precipitation, we have shown that changing all of the biophysical parameters except roughness length and the 
(10a)

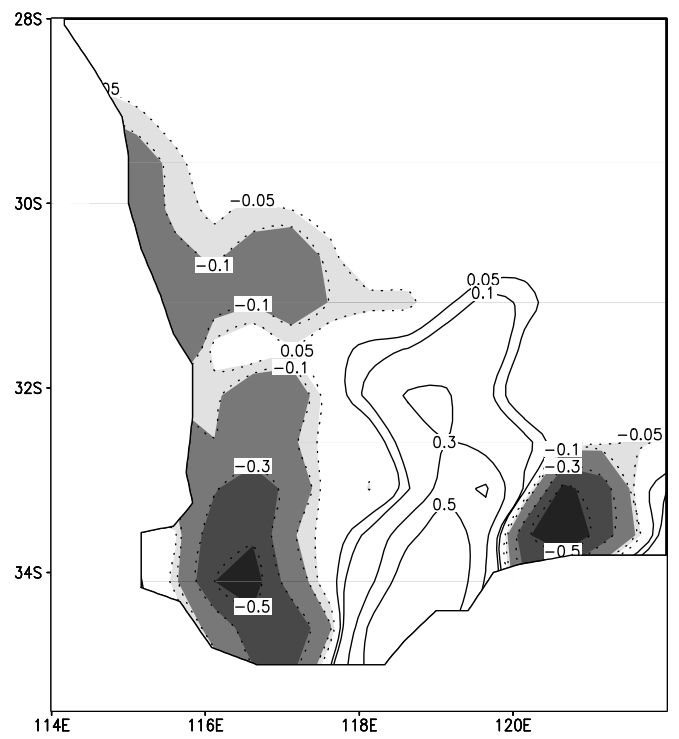

(10c)

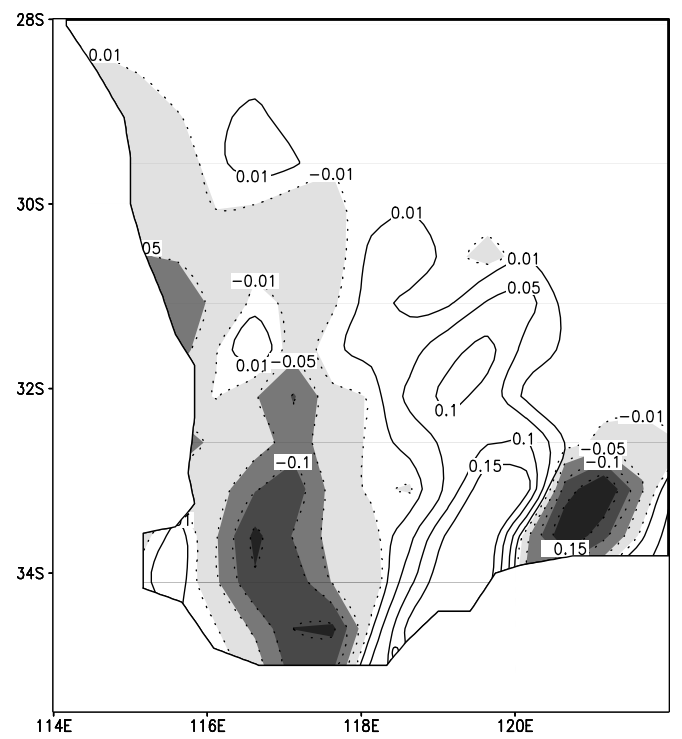

$(10 e)$

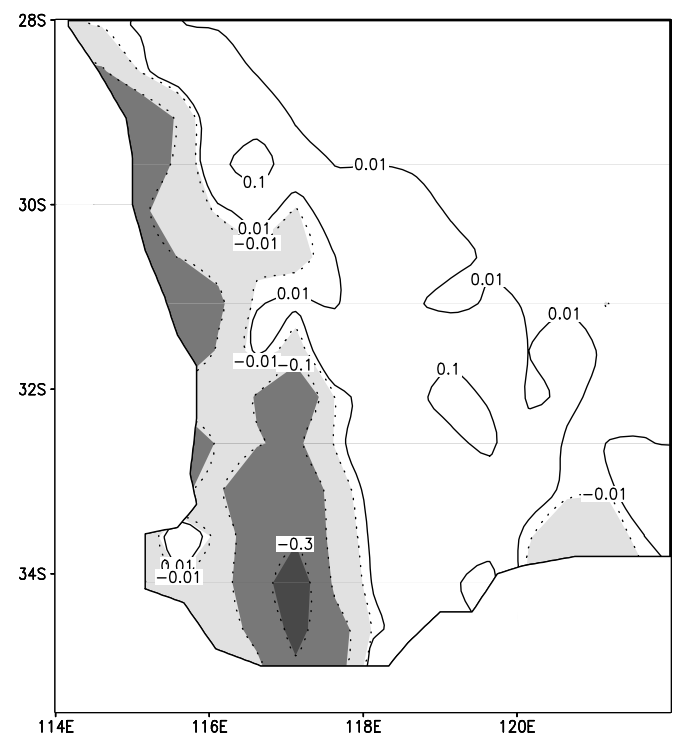

(10b)

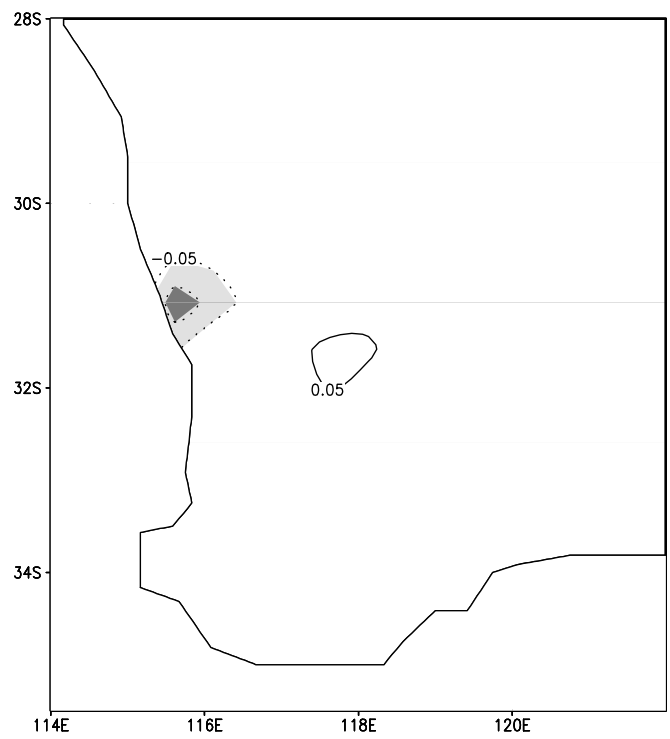

$(10 d)$

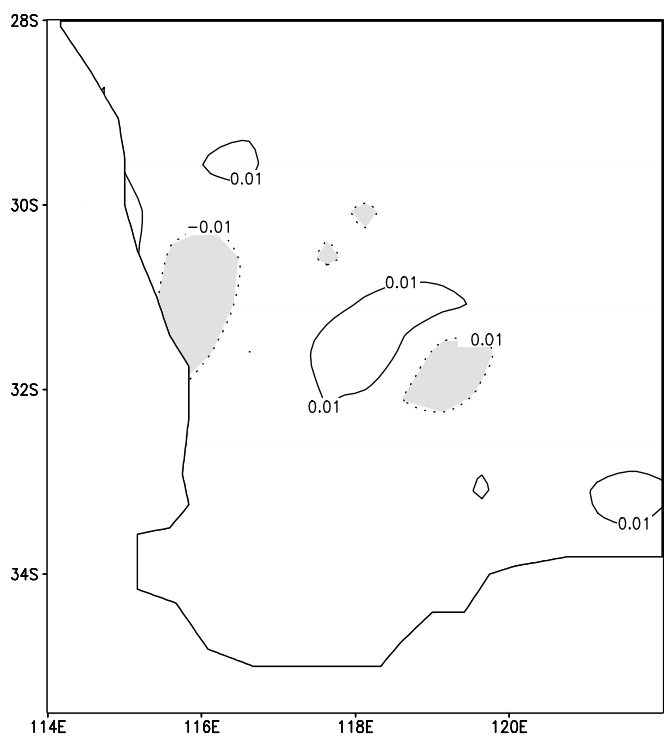

(10f)

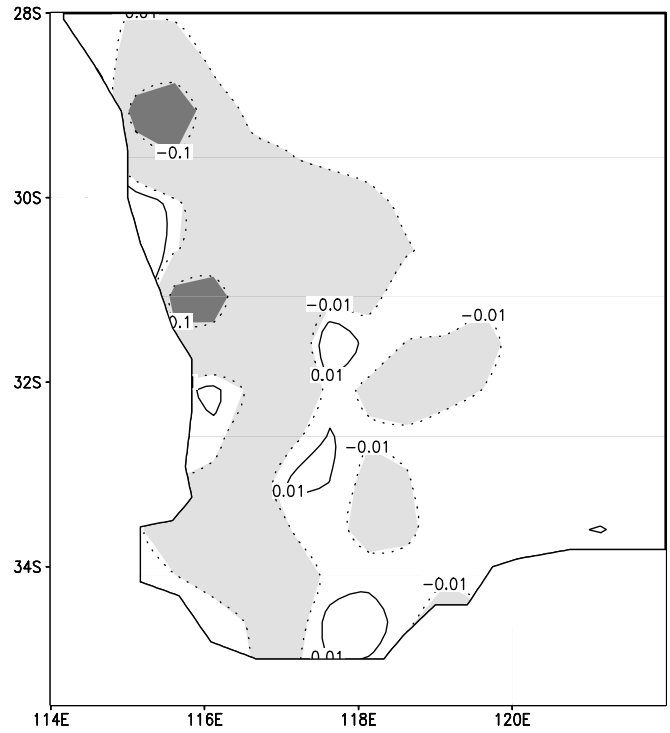

Figure 10

10 of 12 

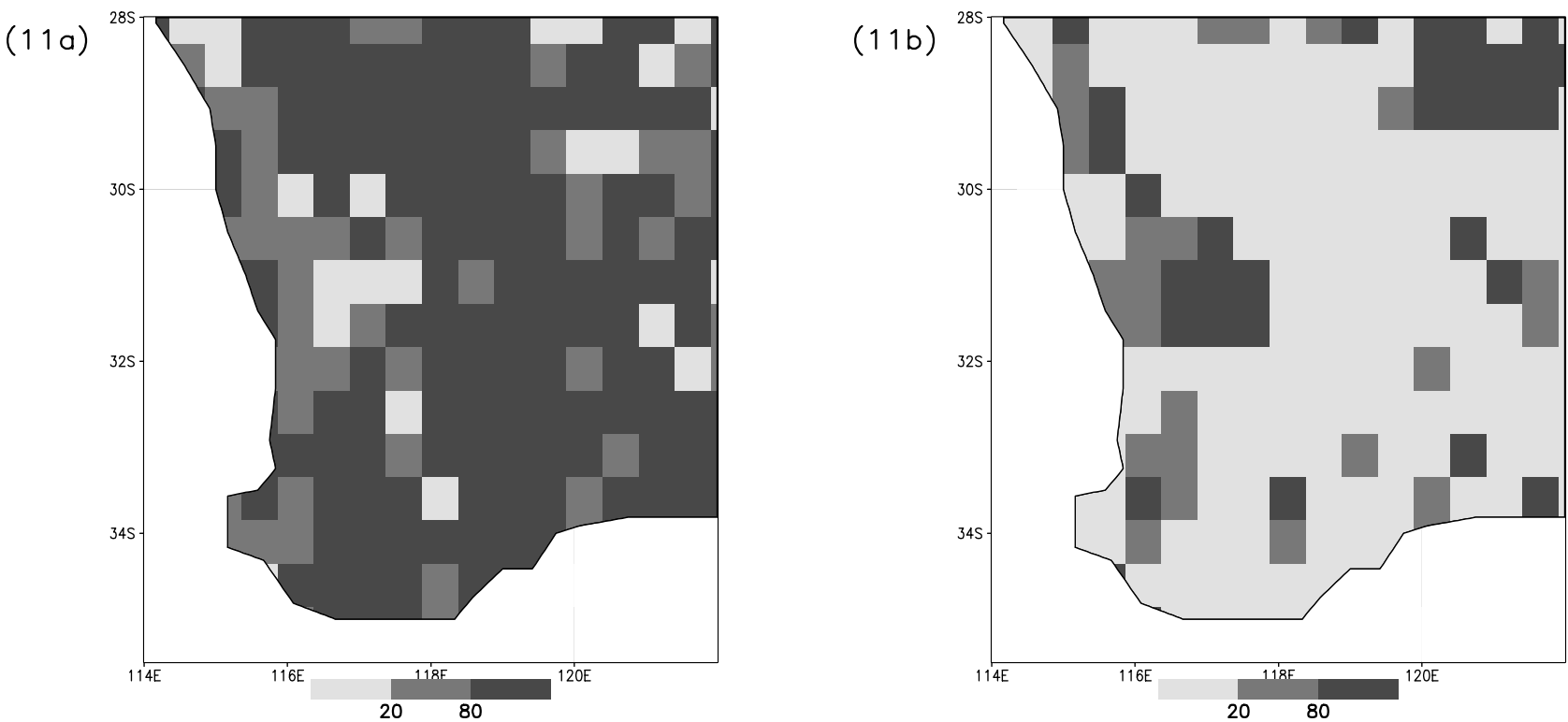

Figure 11. Percentage rainfall change explained by (a) changing just the surface roughness and zero plane displacement height parameters and (b) changing just the moisture supply parameters.

zero plane displacement height led to negligible changes in precipitation (Figures 10f and 11b). In contrast, a change in just the roughness length and the zero plane displacement height could explain the rainfall changes (Figure 10e and 11a). The mechanisms that link these parameters to the changes in rainfall are quite straightforward. The increased wind magnitudes over the regions of LCC (caused by a reduction in the roughness length reducing surface drag) leads to a significant change in the moisture convergence field and the development of a heterogeneous pattern across southwestern Australia. While using natural land cover the moisture convergence pattern is quite homogeneous, replacement by current land cover reduces frictional drag and leads to increased horizontal winds that advect moisture being carried onshore from the Indian Ocean further inland This leads to a divergence of moisture near the coast, extending to between $117^{\circ}$ and $118^{\circ} \mathrm{E}$ (Figure 7). The increased divergence near the coast is balanced by increased convergence from around $118^{\circ} \mathrm{E}$ to $120^{\circ} \mathrm{E}$. The strong convergence in this region leads to increased vertical velocities (Figure 9). The combination of more moisture and increased vertical velocities increases precipitation (Figure 2). This is not a new mechanism: it was used by Polcher and Laval [1994], Kanae et al. [2001], and others to explain the impact of deforestation on regional climates.

[28] IOCI [2002] gave two further arguments against LCC explaining the reduction of rainfall in SWWA. First, they indicated that the strong rainfall reduction toward the coast, and even off the coast at Rottnest Island $\left(32^{\circ} 0 \mathrm{~s}\right.$, $115^{\circ} 27^{\prime} \mathrm{E}$ where LCC has been small) makes it hard to argue that LCC over SWWA could be a dominant factor. Second, they argued that the observed rainfall changes are associated with large-scale patterns of climate variability that are very unlikely to be related to local LCC. We have provided a mechanism to explain why rainfall has reduced to the west of the regions of LCC. The acceleration of the winds over the regions of LCC increases the divergence of moisture to the west, reducing the likelihood of precipitation (we find increased moisture divergence and reduced precipitation over Rottnest Island in our simulations). We have also provided a mechanism whereby LCC causes a large-scale change in the atmospheric circulation pattern over SWWA with up- and down-stream teleconnections. The scale of the LCC perturbation is large and the resulting impact on the wind field and the moisture convergence/divergence is clearly large enough to explain the changes in precipitation.

[29] A final criticism by the IOCI [2002] of the LCC mechanism explaining the rainfall reductions in SWWA is that the change in rainfall was sudden, while the LCC was incremental. We are currently exploring thresholds in the surface-atmospheric interactions over SWWA. We see no reason why the sudden change in precipitation over SWWA could not have been the result of a threshold being reached, whereby up to the 1960s the scale of LCC was too small to generate the large-scale heterogeneity in the moisture convergence, while further LCC in the 1970s generated a sufficient perturbation to force a reorganization in the patterns of moisture convergence. Thresholds of this type exist in complex systems [Rial et al., 2004].

[30] In conclusion, we find strong evidence that observed changes in rainfall and temperature over SWWA can be partially explained by the large-scale LCC. We find that the roughness length and the zero plane displacement height changes affect moisture convergence following a reduction in the drag over the regions of LCC. The changes in moisture convergence and associated changes in vertical

Figure 10. Simulations using LRAMS of change in (a and b) moisture convergence, (c and d) vertical velocity at $280 \mathrm{~m}$, and (e and $\mathrm{f}$ ) rainfall. The left-hand column shows results where only the surface roughness and zero plane displacement height parameters are changed. The right-had panel shows results where only the moisture supply parameters are changed. 
velocities explain the modeled changes in precipitation, changes that bear a strong similarity to the observed changes in this region. We also find a pattern of warming in two of the three models, suggesting that attributing the warming in this region to the enhanced greenhouse effect is premature. The relative role of a large-scale atmospheric reorganization, increasing greenhouse gases and LCC in explaining the observed changes over SWWA remains unknown, but this paper demonstrates that LCC deserves an equal research focus in comparison to alternative mechanisms.

[31] The government of Western Australia, farmers, water providers and users have been profoundly affected by the decline in rainfall $[I O C I, 2002]$. The rainfall decline led to an acceleration in the development of new water sources costing AU\$500 million to respond to a $42 \%$ decrease in the annual inputs to Perth's water supply. Our results demonstrate that this decline could have been caused by largescale LCC. This information empowers policy makers in Western Australia. While the Western Australian government cannot influence global strategies to moderate the enhanced greenhouse effect, they can mitigate changes caused by local land cover change. We suggest that the costs of large-scale reforestation strategies in SWWA would be substantially offset by increasing rainfall, as well as providing a century-scale sink for greenhouse gases to moderate Australia's very high per-capita greenhouse gas emissions.

[32] Acknowledgments. GTN is supported by MUIPGRA scholarship. We thank three anonymous reviewers for their thorough analysis and comment on the submitted version of the manuscript.

\section{References}

Australian Surveying and Land Information Group (AUSLIG) (1990), Atlas of Australian Resources: Vegetation, 64 pp., Commonw. of Aust., Canberra, ACT

Bonan, G. B., D. Pollard, and S. L. Thompson (1992), Effects of boreal forest vegetation on global climate, Nature, 359, 716-718.

Chen, C., and W. R. Cotton (1987), The physics of the marine stratocumulus-capped mixed layer, J. Atmos. Sci., 44, 2951-2977.

Chen, D.-X., and M. B. Coughenor (1994), GEMTM: A general model for energy and mass transfer of land surfaces and its application at the FIFE sites, Agric. For. Meteorol., 68, 145-171.

Cotton, W. R., et al. (2003), RAMS 2001: Current status and future directions, Meteorol. Atmos. Phys., 82, 5-29, doi:10.1007/s00703-001-0584-9.

Dudhia, J. (1989), Numerical study of convection observed during the Winter Monsoon Experiment using a mesoscale two-dimensional model, J. Atmos. Sci., 46, 3077-3107.

Grell, G. A., J. Dudhia, and D. R. Stauffer (1994), A description of the fifthgeneration Penn State/NCAR mesoscale model (MM5), NCAR Tech. Note NCAR/TN-398+STR, 117 pp., Boulder, Colo.

Henderson-Sellers, A., R. E. Dickinson, T. B. Durbidge, P. J. Kennedy, K. McGuffie, and A. J. Pitman (1993), Tropical deforestation: Modeling local- to regional-scale climate change, J. Geophys. Res., 98, $7289-7315$.

Houghton, J. T., Y. Ding, D. J. Griggs, M. Noger, P. J. van der Linden, X. Dai, K. Maskell, and C. A. Johnson (Eds.) (2001), Climate Change 2001: The Scientific Basis, Contribution of Working Group 1 to the Third Assessment Report of the Intergovernmental Panel on Climate Change, 572 pp., Cambridge Univ. Press, New York.
Huang, X., T. J. Lyons, and R. C. G. Smith (1995), Meteorological impact of replacing native perennial vegetation with annual agricultural species, Hydrol. Proc., 9, 645-654.

Indian Ocean Climate Initiative (IOCI) (2002), Climate variability and change in southwest Western Australia, Indian Ocean Clim. Initiative Panel, Perth, Western Australia.

Kain, J. S., and J. M. Fritsch (1993), Convective parameterization for mesoscale models: The Kain- Fritsch scheme, in The Representation of Cumulus Convection in Numerical Models, edited by A. Emanuel and D. J. Raymond, pp. 165-170, Am. Meteorol. Soc., Boston, Mass.

Kalnay, E., and M. Cai (2003), Impact of urbanization and land-use change on climate, Nature, 423, 528-531.

Kalnay, E., et al. (1996), The NCEP/NCAR 40-year reanalysis project, Bull. Am. Meteorol. Soc., 77, 437-471.

Kanae, S., T. Oki, and K. Musake (2001), Impact of deforestation on regional precipitation over the Indochina peninsula, J. Hydrometeorol., $2,51-70$.

Lyons, T. J. (2002), Clouds prefer native vegetation, Meteorol. Atmos. Physics, 80, 131-140, doi:10.1007/s007030200020.

Lyons, T. J., P. Schwerdtferger, J. M. Hacker, I. J. Foster, R. C. G. Smith, and X. Huang (1993), Land atmosphere interaction in a semiarid region: The bunny fence experiment, Bull. Am. Meteorol. Soc., 74, 1327-1334.

Lyons, T. J., R. C. G. Smith, and X. Huang (1996), The impact of clearing for agriculture on the surface energy balance, Int. J. Climatol., 16, 551-558.

Marshall, C. H., R. A. Pielke Sr., and L. T. Steyaert (2003), Crop freezes and land use change in Florida, Nature, 246, 29-30.

Narisma, G. T., and A. J. Pitman (2003), The impact of 200-years land cover change on the Australian near-surface climate, J. Hydrometeorol., 4, 424-436.

Pielke, R. A., Sr. (2001), Influence of the spatial distribution of vegetation and soils on the prediction of cumulus convective rainfall, Rev. Geophys., 39, $151-177$.

Pielke, R. A., Sr., R. Avissar, M. Raupach, A. J. Dolman, X. Zeng, and A. S. Denning (1998), Interactions between the atmosphere and terrestrial ecosystems: Influence on weather and climate, Global Change Biol., 4, $461-475$.

Polcher, J., and K. Laval (1994), A statistical study of the regional impact of deforestation on climate in the LMD GCM, Clim. Dyn., 10, 205-219.

Ray, D. K., U. S. Nair, R. M. Welch, Q. Han, J. Zeng, W. Su, T. Kikuchi, and T. J. Lyons (2003), Effects of land use in southwest Australia: 1. Observations of cumulus cloudiness and energy fluxes, J. Geophys. Res., 108(D14), 4414, doi:10.1029/2002JD002654.

Rial, J., et al. (2004), Nonlinearities, feedbacks and critical thresholds within the Earth's climate system, Clim. Change, 65, 11-38.

Sellers, P. J. (1992), Biophysical models of land surface processes, in Climate System Modeling, edited by K. E. Trenberth, pp. 451-490, Cambridge Univ. Press, New York.

Sellers, P. J., et al. (1997), Modeling the exchanges of energy, water and carbon between continents and the atmosphere, Science, 275, 502-509.

Simmonds, I., and K. Keay (1958), Variability of Southern Hemisphere extratropical cyclone behaviour, 1958-97, J. Clim, 13, 550-561.

Smith, I. N., P. McIntosch, T. J. Ansell, C. J. C. Reason, and K. McInnes (2000), Southwest Western Australian winter rainfall and its association with Indian Ocean climate variability, Int. J. Climatol., 20, 1913-1930.

Walko, R. L., et al. (2000), Coupled atmosphere-biosphere-hydrology models for environmental modeling, J. Appl. Meteorol., 39, 931-944.

Williams, M. (2003), Deforesting the Earth: From Prehistory to Global Crisis, 689 pp., Univ. of Chicago Press, Chicago.

Wright, W. J. (1997), Tropical-extratropical cloudbands and Australian rainfall: I. Climatology, Int. J. Climatol., 17, 807-829.

Xiu, A., and J. E. Pleim (2001), Development of a land surface model. Part I: Application in a mesoscale meteorological model, J. App. Meteorol., 40, 192-209.

N. J. Holbrook, G. T. Narisma, and A. J. Pitman, Department of Physical Geography, Macquarie University, Sydney NSW 2109, Australia. (apitman@penman.es.mq.edu.au)

R. A. Pielke Sr., Department of Atmospheric Sciences, Colorado State University, Fort Collins, CO 80523, USA. 